\title{
Carbon mineralization pathways in Antarctic shelf sediments, East Antarctic Peninsula

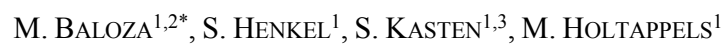

${ }^{1}$ Alfred Wegener Institute Helmholtz Centre for Polar and Marine Research, Am Handelshafen 12, 27570 Bremerhaven, Germany (*correspondence: marwa.baloza@awi.de) ${ }^{2}$ Faculty 2 Biology / Chemistry, University Bremen, Leobener Str., D-28359 Bremen, Germany

${ }^{3}$ Faculty of Geosciences, University Bremen, Klagenfurter Str., Bremen, Germany

The Antarctic continental shelf represents roughly $11 \%$ of the world's continental-shelf area and exhibits the highest areabased primary production rates in the Southern Ocean. On the shelf, primary production strongly varies depending on light conditions, sea ice cover, mixing depth and nutrient availability. In regions impacted by global warming, such as the Antarctic Peninsula, these conditions are changing. The retreat of sea ice and the availability of previously icecovered areas for marine primary production has important repercussions on nutrient and carbon fluxes. In this study, we investigated benthic remineralization processes along a cryopelagic productivity gradient from year-round heavy ice conditions through the marginal ice zone to mainly ice-free conditions at the Western shelf of the Weddell Sea (East Antarctic Peninsula). Carbon mineralization rates were derived from pore-water profiles of oxygen, nitrate, ammonium, dissolved manganese and dissolved iron. Pore water samples were obtained from sediment cores retrieved by multi-coring at water depths between 330 to $455 \mathrm{~m}$. Two deep stations ( $3000 \mathrm{~m}$ depth) were sampled for comparison. While yearly sea ice cover decreased from 80 to $30 \%$ between the stations, benthic carbon oxidation rates increased from 1.0 to $7.6 \mathrm{mmol} \mathrm{C} \mathrm{m} \mathrm{C}^{-2} \mathrm{~d}^{-1}$ and the total organic carbon contents ranged from 0.15 to $1.5 \mathrm{wt} . \%$. The low rates at heavy ice covered shelf stations were comparable to those of deep sea stations further north. Carbon mineralization rates showed that aerobic respiration accounted for $60-95 \%$ of the total carbon degradation. Anaerobic degradation was dominated by denitrification and iron reduction at stations with high sea ice cover, while sulfate reduction was present only at stations with less sea ice cover. Pore water $\mathrm{Fe}^{2+}$ concentrations reached up to $50 \mu \mathrm{mol} / \mathrm{L}$ near the sediment surface and up to $670 \mu \mathrm{mol} / \mathrm{L}$ at about $4 \mathrm{~cm}$ depth, which can lead to a substantial release of $\mathrm{Fe}^{2+}$ to the water column and to a subsequent increase of the iron limited primary production. In summary, the results indicate that future sea ice retreat may lead to a significant increase of benthic carbon mineralization with a subsequent enhancement of the benthic iron efflux. 